\title{
Infection of Oligochaetes, Limnodrilus hoffmeisteri (Annelida: Oligochaeta), in the Nasal Cavity of a Chinese Man
}

\author{
Hongbin Liu', Zhenming Zhang², Guangping Huang ${ }^{3}$, Xiaolong Gu ${ }^{3,4}$, Chunmiao Wang ${ }^{5}$, Yan Wang ${ }^{5}$, Zhimin Lu ${ }^{5, *}$ \\ 1 Department of Pharmacology, Hebei North University, Zhangjiakou, Hebei 075000, China; ${ }^{2}$ The First Affiliated Hospital of Hebei North University, \\ Zhangjiakou, Hebei 075000, China; ${ }^{3}$ College of Veterinary Medicine, China Agricultural University, Beijing 100193, China; ${ }^{4}$ College of Animal Science \\ \&Technology, Hebei North University, Zhangjiakou, Hebei 075000, China; ${ }^{5}$ College of Laboratory Medicine, Hebei North University, Zhangjiakou, \\ Hebei 075000, China
}

\begin{abstract}
The infection by Limnodrilus hoffmeisteri Claparède, 1862 (Oligochaeta: Tubificinae) in humans is relatively uncommon. The present report is to describe an incidental human infection with oligochaetes in the nasal cavity of a Chinese man, a 25-year-old man residing in Zhangjiakou city, Hebei province, China presenting with nose bleed, severe itching, continuous sneezing, and rhinorrhea. A lot of oligochaete worms were found in the nasal discharge of the patient. The detected worms were identified as Limnodrilus hoffmeisteri (Annelida: Oligochaeta) based on morphological and molecular characteristics. This incidental $L$. hoffmeisteri nasal infection is the first case in China and indicates that oligochaete worms can be encountered in humans.
\end{abstract}

Key words: Limnodrilus hoffmeisteri, oligochaete, nasal infection, case report, China

\section{INTRODUCTION}

Oligochaete worms, as the second largest group of the Annelida, occur in a wide variety of freshwater environments $[1,2]$. Within this diverse group, Limnodrilus hoffmeisteri Claparède, 1862 (Oligochaeta: Tubificinae), is one of the most common and abundant aquatic oligochaetes $[3,4]$. The worm is very small and red. Like all other oligochaetes, the species is a hermaphrodite, with a complex reproductive system. Typically, each body segment possesses 4 bundles of chaetae (chitinous bristles projecting from the body). The chaetae, vary considerably in size and shape between families, and consequently are used extensively in identification [5]. The life cycle of this species includes a stage that involves shedding of eggs into aquatic or moist environments with subsequent development into earthworms [6]. These worms are capable of producing high population densities in paddy fields, eutrophic lakes, and rivers $[7,8]$. Thus, bathing, picnicking, or field working without pro-

\footnotetext{
- Received 14 June 2016, revised 12 November 2016, accepted 24 December 2016.

*Corresponding author (huanggp2@163.com)

(C) 2017, Korean Society for Parasitology and Tropical Medicine

This is an Open Access article distributed under the terms of the Creative Commons Attribution Non-Commercial License (http://creativecommons.org/licenses/by-nc/4.0) which permits unrestricted non-commercial use, distribution, and reproduction in any medium, provided the original work is properly cited.
}

tection measures may bring the potential risk of ingress.

Along with helminths and parasitic nematodes, occasional cases of non-parasitic worm infections (caused by Enchytraeus sp., Lumbricillus lineatus, and Limnodrilus hoffmeisteri) have been reported in humans $[9,10]$. However, aquatic oligochaete human infections have not been reported in China up till now.

In this study, we are reporting a case of oligochaete nasal infection in a 25-year-old Chinese man. This is the first observed report of such case in China. After detailed microscopic examinations and molecular identification, the infected specimen was identified as L. hoffmeisteri. The infectious agent was eliminated and was no longer detectable in the patient's nasal cavities after treatment with Zentel ${ }^{\circledR}$ (albendazole). These data will assist clinicians to be aware of this diagnosis and properly guide preventable measures to those who are in risk (such as aquaculture farmers, fishery workers, and ornamental fish hobbyists).

\section{CASE RECORD}

The patient was a 25-year-old male residing in Zhangiiakou city, Hebei province, China employed by a coalmine machinery factory. He initially presented with severe nasal itching, rhinorrhea, and continuous sneezing followed by a nose bleed 2 

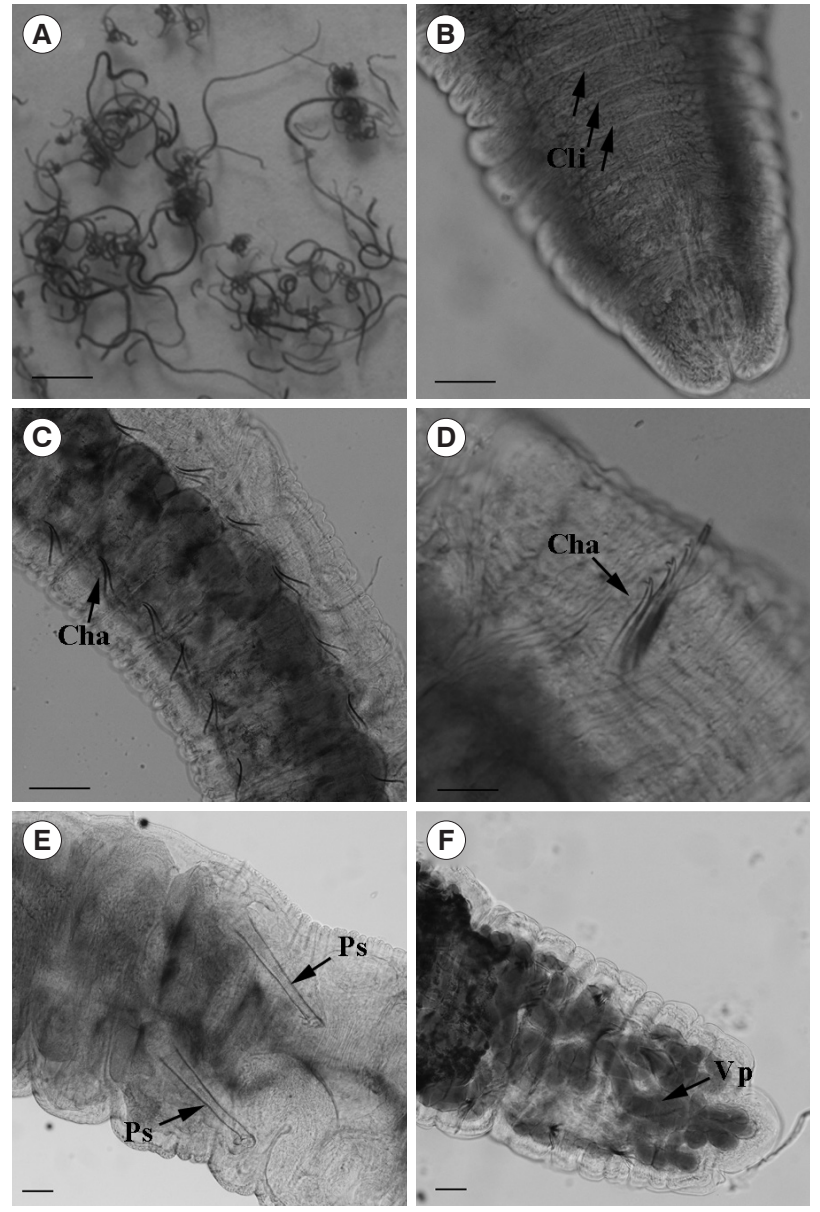

Fig. 1. Photomicrographs of Limnodrilus hoffmeisteri. (A) A large number of worms in the nasal discharge. (B) Anterior part of $L$. hoffmeisteri, lateral view (arrows: clitella). (C, D) Long and thin bifid chaetae (C) with a curved distal end (D) observed on the dorsal pre- and post-clitellar regions. (E) Two different penile sheaths (arrows). (F) Distal end of $L$. hoffmeisteri and vascular plexus (arrows). Scale bars $=500 \mu \mathrm{m}(\mathrm{A}), 50 \mu \mathrm{m}(\mathrm{B}-\mathrm{F})$.

days prior to consultation. Mucosal damage to Kiesselbach's area (on the antero-inferior part of the nasal septum), was diagnosed by nasal endoscopy. High neutrophil levels were observed in the patient's blood. The worms extracted from the nasal discharge of the patient were identified by using morphological and molecular methods.

The observed worm length was $15-45 \mathrm{~mm}$, and worm width was $0.6-0.8 \mathrm{~mm}$ (Fig. 1A). The prostomium of the observed worms was cone-shaped, and contained about 110 proglottids (Fig. 1B). Long and thin bifid chaetae with a curved distal end were observed on the dorsal pre- and post-clitellar regions (Fig. $1 \mathrm{C}, \mathrm{D})$. The ratio of the length of the dorsal bifid chaetae to the ventral chaetae was approximately 1.15 . The penile sheath

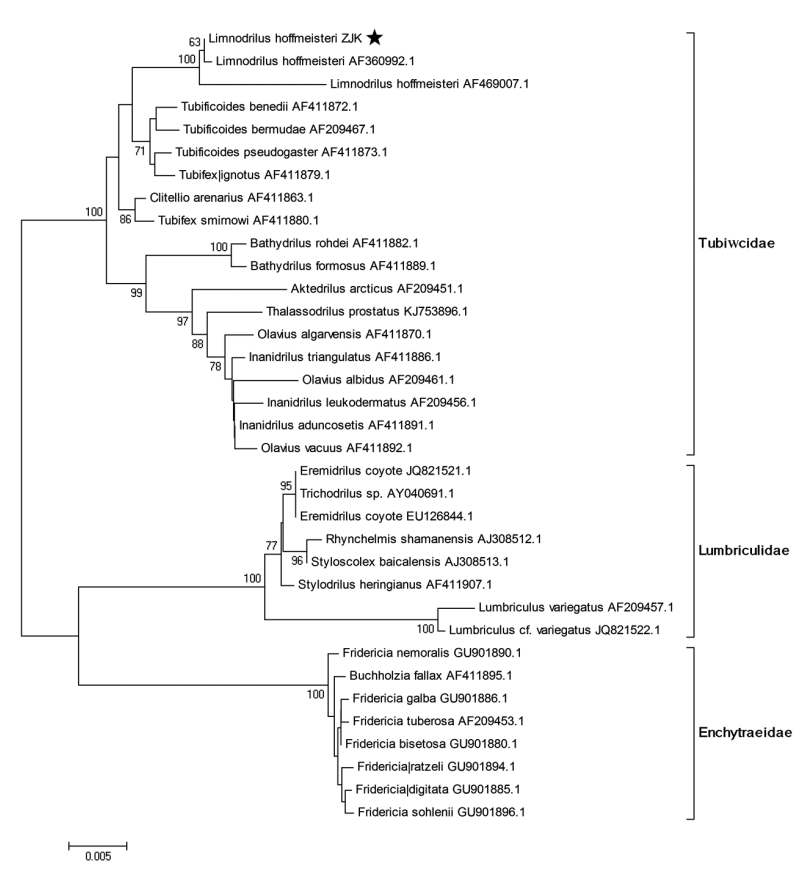

Fig. 2. Neighbor-joining ( $\mathrm{NJ}$ ) tree estimated from the small subunit ribosomal RNA regions of Limnodrilus hoffmeisteri. Nodal values refer to bootstrap support values from 1,000 replicates for $\mathrm{NJ}$.

was long and tubular, and the length to width ratio ranged from 10.3 to 11.3 (Fig. 1E). The morphological characteristics of the species were consistent with a previously published description of L. hoffmeisteri [4].

Furthermore, genomic DNA was extracted from individual worms using a genomic DNA purification kit (Tiangen, China) for amplification of the small subunit ribosomal RNA (rRNA) region (Fig. 2). The sequences obtained showed 99\% identity with L. hoffmeisteri NCBI GenBank entries (nos. AF360992, AF361103). A neighbor-joining (NJ) tree constructed from SSU sequences grouped the worm isolated from the patient into the same cluster as L. hoffmeisteri (Fig. 2).

Together, the morphological characteristics and molecular data confirmed that the species isolated from the patient was $L$. hoffmeisteri. Fortunately, the oligochaete worms were no longer detectable in the patient's nasal cavities following treatment with $400 \mathrm{mg}$ Zentel ${ }^{\circledR}$ (albendazole) and Yunnan Baiyao (also called Yunnan Paiyao [11], a hemostatic powdered medicine) once daily for 6 days. The former treatments also resulted in patient's symptom resolution.

\section{DISCUSSION}

More than 10 species of Limnodrilus have previously been 
described [12]. Of those, L. hoffmeisteri is the best known and is considered to be the dominant species of the genus [13]. This species is widely distributed in freshwater bodies in China. Although uncommon, the infection can occur in people after exposure to contaminated water. In the present study, for the first time we have reported the case of $L$. hoffmeisteri infection in the nasal cavity of a Chinese man. As a result of this study, total 444 live red worms were isolated and examined from the nasal discharge of the patient by the First Affiliated Hospital of Hebei North University. Measurements of $L$. hoffmeisteri, including the body and penile sheath size, prostomium shape, and the ratio of the length of the dorsal bifid chaetae to the ventral chaetae, were performed. The observed measurements for these species-specific parameters were consistent with previous descriptions [12]. Molecular data further confirmed the morphological identification.

Occasionally such worms are obtained from humans as pseudo-parasites. Blakemore et al. [10] reported 2 independent cases of oligochaete recovered from the vagina of Korean women. The specimens were identified as microdrile tubificid L. hoffmeisteri Claparède, 1862 (Tubificidae) and megadrile dichogastrid Dichogaster bolaui Michaelsen, 1891 (Octochaetidae), respectively. In our study, we demonstrated a case of human nasal infection with $L$. hoffmeisteri in China. However, the exact route of infection remains unclear. The likely source of infection of the Chinese patient was fish bait used by the patient to feed domestically maintained tropical fish. It is likely that finger-to-nose contact with the fish bait gave rise to the associated infection. A second potential infection source may be a local reservoir used by the patient for recreational purposes 6 months prior to the infection.

Such opportunistic infection by L. hoffmeisteri occurs more frequently in individuals who are exposed to aquatic environments through labor occupation or leisure activities, usually with skin or mucosal lesions, paresthesia or itching at the ingress site, as well as associated systemic manifestations [9]. Accurate identification of pathogenic agents of these opportunistic infections is critical for the proper selection of clinical complementary tests and detailed anamnesis [14]. To summarize, this is the first report of nasal infection with $L$. hoffmeisteri in a human in China. This L. hoffmeisteri nasal infection can serve as a reminder that oligochaete worms can result in human infections. This also demonstrates that appropriate hygiene precautions are important during field working and leisure activities.

\section{ACKNOWLEDGMENT}

This study was supported by the Innovative Talents Cultivation Foundation of Hebei North University (grant no. CXRC1326).

\section{CONFLICT OF INTEREST}

We have no conflict of interest related to this work.

\section{REFERENCES}

1. Poinar GO. Association between nematodes (Nematoda) and oligochaetes (Annelida). Proc Helminthol Soc Wash1978; 45: 202-220.

2. Ragi MS, Jaya DS. Distribution and diversity of oligochaetes in selected ponds of Thiruvananthapuram district, Kerala, South India. Adv Microb Ecol 2014; 1-9.

3. Ohtaka A, Mawatari SF, Katakura H. Morphological and habitat differences between two forms of Japanese Limnodrilus hoffmeisteri Claparède (Oligochaeta, Tubificidae). J Fac Sci Hokkaido Univ (Ser. Zoology) 1990; 25: 106-117.

4. Claparède É. Recherches anatomiques sur les Oligochètes. Mem Soc Phys Hist Nat Geneve 1862; 16: 71-164.

5. He XB, Cui YD, Wang HZ. Limnodrilus simplex sp. nov. (Oligochaeta: Naididae: Tubificinae) from Changiiang River, China. Zool Sci 2010; 27: 768-770 (in Chinese).

6. Young JO. Life-cycles of some invertebrate taxa in a small pond together with changes in their numbers over a period of three years. Hydrobiologia 1974; 45: 63-90.

7. McGinnis S, Kerans BL. Land use and host community characteristics as predictors of disease risk. Landsc Ecol 2013; 28: 2944.

8. Friend H. The bionomics of English oligochaeta. II. British Enchytraeides: the role of Pachydrilus. Sci Prog 1916; 11: 12-22.

9. Ryujin M. Case report on a parasitism of earthworms in human. Eisei Dobutsu 1952; 3: 98-99 (in Japanese).

10. Blakemore RJ, Lee W, Ryu JS, Ahn MH, Kim SR. Accidental vaginal parasitism by oligochaete worms (Annelida: Oligochaeta). Opusc Zool Inst Zoosyst Oecol Univ Bp 2012; 43: 197-201.

11. Ladas EJ, Karlik JB, Rooney D, Taromina K, Ndao DH, Granowetter L, Kelly KM. Topical Yunnan Baiyao administration as an adjunctive therapy for bleeding complications in adolescents with advanced cancer. Support Care Cancer 2012; 20: 3379-3383.

12. Richards OW. A guide for the identification of British aquatic Oligochaeta. Freshw Biol 1963; 22: 52.

13. Brinkhurst RO, Rodriguez P, Chon TS, Kwon TS. A new genus of Lumbriculidae (Oligochaeta) from Korea. Can J Zool 1994; 72: 1960-1966.

14. Sette CS, Wachholz PA, Masuda PY, da Costa Figueira RB, de Oliveira Mattar FR, Ura DG. Mycobacterium marinum infection: a case report. J Venom Anim Toxins Ind Trop Dis 2015; 21: 7. 